\title{
Escola justa e organização escolar: a percepção de professores brasileiros do ensino médio
}

\author{
Fair school and educational management: the perception of brazilian teachers \\ of high school \\ Escuela justa y organización escolar: la percepción de profesores brasileños \\ de la enseñanza secundaria \\ DINAIR LEAL DA HORA \\ LUZIANE SAID COMETTI LELIS
}

\begin{abstract}
Resumo: $O$ presente trabalho apresenta os resultados iniciais da pesquisa intitulada "Os significados de escola justa para estudantes e professores brasileiros da Educação Básica, para verificar o significado que estudantes e professores do ensino médio público e privado atribuem para justiça; identificar suas representações a respeito de escola justa e, discutir a organização escolar, a partir dos significados de escola justa atribuídos por esses sujeitos". Nosso estudo recaiu sobre a estruturação da experiência escolar no sentido de tornar visíveis as (in)justiças que a compõem, sejam elas relacionadas com as (des)igualdades, com a redistribuição, com a falta de reconhecimento, com o desrespeito, com a não participação nos órgãos de decisão.
\end{abstract}

Palavras-chave: educação e justiça; cidadania; gestão educacional.

\begin{abstract}
The present paper presents the initial results of the research entitled the meanings of a fair school for Brazilian students and teachers of basic education. It aims at verifying the meaning that students and teachers of public and private high schools attribute to justice, their representations regarding fair school as well as to discuss the school organization based on the meanings of a fair school attributed by these subjects. Our study focuses on the structuring of the school experience in order to make visible the (un)equalities that are part of it, whether they relate to (un)equalities, redistribution, lack of recognition, disrespect, or the non-participation in decision-making bodies.
\end{abstract}

Keywords: Education and justice; citizenship; educational management.

Resumen: El presente trabajo presenta los resultados iniciales de la investigación titulada Los significados de escuela justa para estudiantes y profesores brasileños de la educación básica, para verificar el significado que estudiantes y profesores de la enseñanza secundaria pública y privada atribuyen a la justicia; identificar sus representaciones con relación a la escuela justa y discutir la organización escolar, desde los significados de escuela justa atribuidos por esos sujetos. Nuestro 
estudio recayó sobre la estructuración de la experiencia escolar en el sentido de tomar visibles las (in)justicias que la componen, estén ellas relacionadas a las (des)igualdades, con la redistribución, con la falta de reconocimiento, con la falta de respeto, con la no participación en los órganos de decisión.

Palabras clave: Educación y justicia; ciudadanía; gestión educativa.

\section{INTRODUÇÃO}

O tempo atual apresenta-se com grande vulnerabilidade social, em que noções como precariedade e desemprego, emprego temporário, diferenciação, debilidade do movimento social, individualização das relações sociais, desigualdades, insegurança, incerteza, desregulação, fragilidade dos laços comunitários, feminização da pobreza, desqualificação e atomização social demarcam um campo semântico claro de inquietações profundas, apontando para as múltiplas formas como muitos são atingidos por um trabalho de verdadeira decomposição, de ressocialização que os vulnerabiliza como seres humanos.

Nossas sociedades desiguais, marcadamente injustas e excludentes, não só não conseguiram cumprir uma das promessas da modernidade que apontava para a gestão controlada das desigualdades através de políticas redistributivas e do pleno emprego, como veem agora manifestar-se, por novos processos econômicos, políticos e culturais, novos sistemas de desigualdades, seja no campo da educação, no da economia, no da cultura ou no da política. Hoje, raciocina-se não tanto em termos de igualdade, mas, antes, em parâmetros de custo e eficácia, de maximização da eficiência mercantil, independentemente dos efeitos de exploração, competição e desigualdade que geram, acolhendo-se pacificamente a ideia, por exemplo, de que é exigência de progresso a separação entre o econômico e o social, devendo pugnar-se simultaneamente pela integração econômica e pela desintegração social.

Ao mesmo tempo, os movimentos de globalização levam-nos a colocar na ordem do dia a questão da justiça, uma vez que, também aqui, assistimos ao fato de a argumentação sobre a justiça estar a alterar-se, salientando a pluralidade de sentidos consoante às várias definições, perspectivas e teorias sociais de que partimos, ao mesmo tempo que se exige outro paradigma, o da "justiça democrática pós-Westfaliana" (FRASER, 2007, p. 37).

Esse novo paradigma impõe a todos os setores, mormente à educação, novas exigências, designadamente em termos de aprofundamento de suas raízes democráticas e participativas, pugnando por maior simetria estrutural de poder, nos diferentes níveis de relações sociais (relações de trabalho, organizações, interações, tomada de decisões...). Impõe também a consideração das várias 
facetas da justiça, entendendo-a não apenas como questão redistributiva, mas também de reconhecimento e de participação em vários níveis, tendo presente a especificidade dos contextos em que se concretiza (ESTEVÃO, 2009).

Obviamente, esse enquadramento não pode deixar de apontar para a centralidade das tensões e conflitos que essas diferentes dimensões implicam entre si, uma vez que, tal como defende Young (1990), nem todas as questões de justiça são redutíveis à distribuição, como é o caso, por exemplo, das questões resultantes da (injustiça da) normalização, que eleva a experiência e as capacidades de alguns segmentos sociais a padrões diante dos quais alguns comportamentos podem ser medidos e considerados desviantes. Para essa autora, a justiça social exige desmantelar as estruturas de opressão e dominação, embora essas duas faces não digam respeito apenas ao modo como os recursos são distribuídos. Acrescenta, ainda, que a opressão apresenta cinco faces (exploração, marginalização, ausência de poder, imperialismo cultural e violência) que não são redutíveis a uma única fonte comum tal como não são solucionadas pela distribuição de recursos de modo igualitário.

Em suma, independentemente de alguns autores tenderem a acentuar a justiça como distributiva ou econômica, que inclui, segundo Fraser (1997), a ausência de exploração, marginalização e privação material (embora a justiça distributiva possa incluir também aspectos acerca da distribuição de recursos sociais e culturais), ou de outros pretenderem sublinhar a justiça, sobretudo como justiça de reconhecimento, referida à ausência de dominação cultural, não reconhecimento e desrespeito, nas palavras de Fraser, (2009) ou como ausência da opressão e da dominação segundo Young (1990).

Não deixa de ser verdade que outros apontam para outra dimensão da justiça, a participativa ou de associação, que tem a ver com os padrões de associação entre indivíduos ou grupos que os impedem de participar totalmente nas decisões que afetam as condições em que eles vivem e atuam (POWER; GEWIRTZ, 2001, p. 41).

É consensual que a escola pouco se tem modificado desde a modernidade, reproduzindo as mesmas desigualdades, embora vá produzindo e multiplicando novas desigualdades também, conectadas com a relevância que determinados mundos e suas racionalidades assumem em seu interior.

Tal como a vida social é organizada segundo vários referenciais ou princípios reguladores, também a escola se constitui num lugar de vários mundos ou racionalidades, fato esse que justifica várias definições da sua realidade organizacional.

A escola é, com efeito, uma organização complexa, uma rede de relações sociais materiais que organizam a experiência cotidiana e pessoal do aluno, uma 
organização que apresenta várias faces e na sua acústica soam várias vozes e várias justiças. Aliás, é frequente usarmos na escola diferentes léxicos e registros, movendo-nos entre a velha linguagem do serviço público (linguagem da igualdade de oportunidades), as novas linguagens da gestão escolar e a linguagem do mercado (relações públicas, marketing, recrutamento); a linguagem da gestão financeira (orçamento); a linguagem da gestão organizacional (cultura organizacional, recursos humanos, qualidade, testes)... Tudo isso numa sobreposição clara de diferentes registros cognitivos obtidos por trocas comunicativas no interior da escola.

$\mathrm{Na}$ verdade, se existe multiplicidade e polimorfia dos princípios regulatórios na educação e na escola, torna-se logicamente defensável a afirmação de uma "dialetologia da justiça e dos direitos" na "ordem escolar", embora esta nem sempre seja muito visível devido à hegemonia e dominação da justiça oficial, ancorada, como sublinha Dubet (2004, na figura cardinal da "igualdade meritocrática de oportunidades" (p. 6), típica das sociedades democráticas que consideram todos os indivíduos livres e iguais em princípio, embora admitindo sua distribuição em posições sociais desiguais. Ou seja, a relação entre os sistemas educativos e as doutrinas da igualdade de oportunidades e do mérito, sob a capa da justiça legitima nas sociedades democráticas liberais a própria hierarquia social.

Nesse sentido, o contributo da noção de "justiça complexa” (ou dos vários princípios de justiça) permite, desde logo, questionar a pertinência do conceito unívoco de justiça escolar, que, sob a forma de equidade formal e universal (e que tende a definir-se como o critério de cada um receber de acordo com a sua contribuição), reproduz de fato, embora de forma velada, uma pluralidade de formas de injustiça. De outro modo, a escola é compreendida como uma organização plural, como uma arena de plurirracionalidades, de coordenação, de princípios argumentativos, de lógicas compósitas de justificação, ou de concepções plurais de justiça, obrigando por isso os atores educativos a coordenarem as suas ações, resolvendo os seus conflitos e dissensos locais, aprendendo, enfim, a passar de um sistema de referência ou de justificação para outro, a negociar interpretações diferentes da realidade escolar para que a escola, apesar de tudo, funcione com normalidade ou, pelo menos, dentro de regras mínimas de convivência e de uma coerência aceitável (DUBET, 2002).

Isso reforça a ideia de que os sujeitos escolares estejam, por um lado, despertos para um trabalho incessante e contínuo de justificação e de construção permanente deles mesmos no sentido de se tornarem verdadeiramente sujeitos, e, por outro, que estejam preparados para a negociação sobre a definição legítima da situação, tendo em vista a construção política de acordos ou de compromissos, assim como para a compreensão dos mecanismos de produção de "novas 
legitimidades educativas". Assim sendo, a ação organizacional escolar se explica não apenas pela socialização, mas também, pela economia das "razões práticas" ou das "boas razões" que reenviam, entre outros aspectos, a lógicas de comunicação contextualizadas (DUBET, 2002, p. 69).

Partindo desse enquadramento, torna-se particularmente interessante analisar como a própria experiência escolar dos alunos é argumentada em vários registros de justiça (por apelos ao mérito, à igualdade, à participação e ao respeito, à discriminação positiva, ao mínimo essencial educativo, às oportunidades de saídas profissionais, por exemplo), diante da atuação dos professores, das interações que são privilegiadas, das práticas de avaliação adotadas, dos procedimentos disciplinares, das implicações da pedagogia a que se perfilham.

Contudo, é preciso ter clareza de que os conceitos de justiça e de práticas justas são mediados por outras variáveis, especialmente a que tem a ver com a desigual distribuição de capital político, social e econômico dos alunos, com a especificidade dos contextos em análise, para além dos níveis que privilegiamos para realizar a investigação (ver GEWIRTZ, 2006).

Independentemente dessa percepção, a priori o desejo de justiça escolar parece ser indiscutível, como diria Dubet (2004). Porém, tal compreensão não facilita a tarefa de definir uma escola justa, dado que existem diferentes maneiras de defini-la, nem sempre compatíveis entre si. Por exemplo, os estudantes com problemas de aprendizagem/comportamento podem estar em desvantagem numa das duas dimensões (redistribuição e reconhecimento) e a escola investir no sentido de ultrapassá-la, ou então verificar se o fato dos estudantes serem injustiçados no duplo registro da distribuição e do reconhecimento, ao ser-lhes negado o acesso aos recursos educacionais e ao mesmo tempo serem culturalmente marginalizados ao serem tratados como crianças-problema. Noutros termos, a justiça meritocrática, apanágio das sociedades liberais democráticas, pode virarse contra a justiça cívica ou cidadã, privilegiando outros valores mais de pendor industrial ou gerencialista.

Quando discutimos o conceito de justiça, não no sentido jurídico-formal, mas no sentido eminentemente político, ético, cultural e sociológico, é preciso perceber sua íntima relação com os conceitos de igualdade, equidade, liberdade, mérito, poder, autoridade, entre outros, que condicionam, de modo particular, a maneira como pensamos a educação e a forma como as escolas se organizam para cumprirem suas finalidades.

O emprego do recurso de uma sociologia de justiça, para analisar o conceito de justiça, tendo em conta o contexto educacional e o espaço escolar, permite um mergulho profundo nos problemas da educação para compreender 
melhor como se constrói sua regulação (pelo Estado ou pelo mercado, por exemplo) ou o modo como ela contribui para reforçar ou fragilizar o pilar da emancipação.

Ora, se a justiça diz respeito às questões essenciais da igualdade, da liberdade e da democracia, ela acaba por ser outro nome da educação, de uma boa educação. Tanto que muitos estudiosos acatam esta indissociabilidade e, entre eles, Sturman (1997) considera que "no contexto escolar a justiça social não é algo de diferente da educação" (p.124).

Apesar da articulação orgânica entre justiça e educação, a justiça, mesmo nas análises mais consistentes que orientam as políticas educacionais, tem sido um conceito subteorizado e assim não consegue assumir protagonismo no campo educacional.

Quando claramente invocada, a justiça na educação é relacionada, fundamentalmente, com o princípio da igualdade de oportunidades, com o mérito, com o respeito e, até, mais recentemente, com a eficiência, com a qualidade e com a competição.

Considerar o princípio singular da igualdade de oportunidades, de inspiração liberal, na atualidade, revela uma tendência restritiva, já que este princípio acentua a função da escola de fornecer oportunidades e não satisfações, aberturas limitadas e não direitos inalienáveis.

Num contexto em que há prevalência da lógica de mercado, o princípio da igualdade de oportunidades torna-se um meio para deformar o próprio princípio da igualdade educativa, já que funciona como um mecanismo de legitimação das desigualdades. Pode, objetivamente, justificar a desigualdade na obtenção de outros benefícios a que a educação dá acesso (emprego, por exemplo).

Lynch (1995) propõe a compreensão da igualdade como igualdade de condição, já que "estaria comprometida com a igualdade das condições de vida de todos os membros da sociedade, considerando a heterogeneidade que advém de gênero, etnicidade, deficiência, religião, idade, orientação sexual ou de qualquer outro atributo" (p. 18). A igualdade de condição, assim, diz respeito não apenas à igualização de posição (acesso, participação e resultados) de grupos marginalizados, mas em igualização de riqueza, do poder e dos privilégios. Essa concepção é ampliada pela formulação de Young (1990) de que justiça é a libertação das relações de opressão.

Segundo Gewirtz (2002), essa concepção relacional de justiça pode aplicar-se às políticas educativas, já que elas podem apoiar, interromper ou subverter: 
a) as relações de exploração nas escolas e fora das escolas, visíveis nas estruturas e práticas que podem produzir interações sociais baseadas em pressupostos classistas, racistas, sexistas, etc.;

b) os processos de marginalização e inclusão nas escolas e noutros contextos;

c) a promoção de relações baseadas no reconhecimento, respeito, cuidado e mutualidade, ou o enfraquecimento do poder de alguns sujeitos e/ou grupos;

d) as práticas violentas no sistema escolar e fora dele.

Ainda a propósito da igualdade ou da desigualdade em educação, é preciso considerar que a escola é uma das grandes intervenientes no jogo da desigualdade, embora não a única, e são três os contextos nucleares inter-relacionados geradores de desigualdade em educação, que podem atuar simultaneamente: o socioeconômico; o sociocultural e o político.

No contexto socioeconômico, o problema da igualdade é, sobretudo, redistributivo (de riqueza ou de recursos). No sociocultural (etnicidade, orientação sexual), a causa da desigualdade prende-se à falta de reconhecimento (invisibilidade) ou ao falso reconhecimento (estereótipos negativos) da diferença, o que significa que o problema aqui tem a ver com o status e a identidade. No contexto político, encontramos as relações de poder relacionadas com as questões de justiça e injustiça, com as questões de igualdade ao nível dos interesses (de professores, alunos, responsáveis, servidores) no interior da escola, uma vez que ali também as relações de dominação e subordinação adquirem um modo particular de institucionalização (Fraser, 2009).

Assim, a desigualdade na sociedade e na educação não é apenas uma questão de justiça distributiva (sociopolítico); é também um problema de reconhecimento, porque relativo ao modo como as diferenças de gênero, sexuais, religiosas, étnicas, ou outras são geridas; tem a ver com as questões de representação e com o modo como as relações de poder são resolvidas e, finalmente, é uma questão afetiva, porque diz respeito às relações de dependência e interdependência, o que exige o atendimento às dimensões afetivas da justiça social no interior da escola.

O tema da justiça está intimamente articulado com o das desigualdades e esse, por sua vez, com as noções amplas de redistribuição, reconhecimento e representação. Isso significa que a noção de justiça é complexa, englobando várias dimensões que, na prática, podem colidir entre si ou manter-se em estado de tensão.

No campo da educação, e não obstante a pesada tradição da sua ocultação, a justiça tem vindo a ser resgatada, emergindo como um conceito 
também multidimensional e como um outro nome da educação, pela capacidade de reconhecer o poder dos atores educativos na qualidade de pessoas com direitos culturais, políticos e sociais.

Neste texto procuramos questionar a justiça e as desigualdades, com incidência particular no modo como se (des)multiplicam no contexto educativo, tendo presente que a educação mobiliza diferentes registros, quer valorativos que apelam ao mérito, quer estatutários que obrigam ao respeito por determinados princípios (como o da igualdade de acesso ao bem educativo), quer como expressivos, que favorecem o desenvolvimento e a autonomia dos jovens.

Contudo, essa problematização tem presente também que a própria escola condiciona a compreensão do que se entende por justiça e por práticas educativas justas, devendo ser interpretada como lugar de vários mundos, estruturada segundo os diferentes significados dos princípios de justiça, ora mais cívica, doméstica ou expressiva, ora mais gerencialista ou mercantil.

Dessa forma, o foco do presente artigo recaiu sobre a estruturação da experiência escolar, no sentido de tornar visíveis as (in)justiças que a compõem, sejam elas relacionadas com as (des)igualdades, com a redistribuição, com a falta de reconhecimento, com o desrespeito, com a não participação nos órgãos de decisão, privilegiando, no entanto, o modo pelo qual estudantes e professores do ensino médio, de escolas brasileiras, públicas e privadas, posicionam-se frente aos princípios de justiça explicitamente assentados no mérito, na igualdade, no respeito e na participação.

Consideramos que, quando o sistema educativo se organiza em torno da "igualdade simples" e se reduz à ideia de ser "o mesmo para todos", trata a educação como um bem (bolo) a se distribuir equitativamente tornando-se indiferente às tiranias que podem possibilitar a alguns controlarem mais facilmente, por exemplo, o acesso à educação, por dominarem outros bens (pela riqueza ou pelo poder político que possuem).

Por esse princípio, se os alunos passam a ser vistos como detendo as mesmas necessidades em termos de saber, a quem devem ser ensinadas as mesmas coisas como se fossem um só e a ser tratados como meros alunos que necessitam apenas de conhecimento, corre-se o risco de ensinar a alguém que não existe.

Pensamos que as discussões, as propostas e as práticas que possam superar as desigualdades na educação e considerar a diversidade precisam ser orientadas pelas concepções e pelos critérios de justiça complexa. 


\section{MATERIAIS E MÉTODOS}

Para alcançar os objetivos propostos neste estudo, privilegiamos o emprego de técnicas qualitativas para a obtenção de informações, uma vez que possibilitam o exame acurado dos diferentes aspectos presentes nas concepções e nas relações de justiça no interior da escola e as repercussões que provocam nos sujeitos sociais que constroem o espaço educativo.

A organização metodológica deste trabalho foi delineada em duas partes: a primeira parte, designada pesquisa bibliográfica aprofundada, ofereceu a fundamentação conceitual para análise e registrou os movimentos históricos e as dimensões do conceito de justiça, discutidos e articulados conceitos como desigualdades, cidadania, ética, direitos educacionais, participação.

A segunda parte cuidou da realização de entrevista semiestruturada, quando foram ouvidos, em grupos de discussão, dez professores - cinco de escolas públicas e cinco de escolas privadas do Rio de Janeiro - organizados em quatro grupos de discussão para uma entrevista semiestruturada de aprofundamento sobre justiça, escola justa, cidadania, para aprofundar os sentidos de justiça escolar e obter assim mais informação sobre a experiência de vida dos professores. O uso da técnica de observação das práticas e das relações organizativas que se tecem no interior da escola intencionou revelar os movimentos (in)justos e de des(igualdade) concretos e o modo como se manifestam. Foram alvo de observação as mais diferentes atividades, como reuniões de planejamento, de estudos, pedagógicas, administrativas, de pais e professores, de conselho de classe, de conselho de escola, atividades avaliativas, atividades rotineiras etc.

A análise de informações foi realizada por meio de análise de discurso e análise de enunciação. Assim, nosso estudo recaiu sobre a estruturação da experiência escolar no sentido de tornar visíveis as (in)justiças que a compõem, sejam elas relacionadas com as (des)igualdades, com a redistribuição, com a falta de reconhecimento, com o desrespeito, com a não participação nos órgãos de decisão, privilegiando, no entanto, o modo pelo qual professores do Ensino Médio de escolas brasileiras, públicas e privadas, posicionam-se frente aos princípios de justiça explicitamente assentados no mérito, na igualdade, no respeito e na participação.

Para a análise das informações dos sujeitos da pesquisa, são adotados os procedimentos de análise de discurso, considerada como

Uma proposta crítica que busca problematizar as formas de reflexões estabelecidas, situada enquanto objeto teórico porque: a) pressupõe a linguística, mas se destaca dela: não é nenhuma teoria descritiva, nem uma teoria explicativa. Pretende ser uma teoria crítica que trata da determinação histórica dos processos de significação; 
b) considera como fato fundamental a relação necessária entre linguagem e o contexto de sua produção, juntando para a compreensão do texto as teorias das formações sociais e as teorias da sintaxe e da enunciação; c) pela sua especificidade, ela é cisonista em dois sentidos: 1) procura problematizar as evidências e explicitar seu caráter ideológico, revela que não há discurso sem sujeito e nem sujeito sem ideologia; 2) denuncia o encobrimento das formas de dominação política que se manifestam numa razão disciplinar e instrumental.” (ORLANDI, 1987, p. 11-13)

Pela análise de discurso pretendíamos desvendar o sentido da comunicação dos discursos emitidos nas respostas dos professores, pela qual foi buscada a revelação das contradições, das convergências, das divergências e dos equívocos presentes nos conceitos de justiça, cidadania, participação.

Para a compreensão das percepções dos professores sobre e as características de escola justa apontadas, especialmente no confronto das respostas obtidas nas escolas públicas e nas escolas privadas foi empregada a análise de enunciação que, como diz Minayo (1996),

Considera que na produção da palavra elabora-se ao mesmo tempo um sentido e operam-se transformações. Por isso o discurso não é um produto acabado, mas um momento de criação de significados com tudo o que isso comporta de contradições, incoerências e imperfeições. Leva em conta que, nas entrevistas, a produção é ao mesmo tempo espontânea e constrangida pela situação. Portanto a análise de enunciação trabalha com: a) as condições de produção da palavra. Parte do princípio que a estrutura de qualquer comunicação se dá numa triangulação entre o locutor, seu objeto de discurso e o interlocutor. Ao se expressar, o locutor projeta seus conflitos básicos através de palavras, silêncios, lacunas, dentro de processos, na sua maioria, inconscientes; b) o continente do discurso e suas modalidades (p. 206)

Esses procedimentos trataram o volume das informações contidas nas comunicações como categorias conceituais, de modo que ultrapassem os elementos meramente descritivos, buscando interpretar e compreender as concepções de justiça e as práticas escolares que concretamente emergirão das falas dos professores.

\section{RESULTADOS PRELIMINARES}

Neste trabalho, apresentamos depoimentos de cinco professores do Ensino Médio, a respeito de justiça, escola justa, justiça e injustiça na profissão, injustiças cometidas e sugestões para a efetivação da escola justa. 


\section{O SIGNIFICADO DE JUSTIÇA PARA PROFESSORES}

Prof. A - Justiça nos remete à igualdade. Eu sempre penso na palavra igualdade. Nivelar. Então eu tenho tentado sempre usar a justiça para nivelar, trazer os alunos a um nível acima do deles, pra que eles possam realmente evoluir.

Prof. B - Como professora, a justiça está no reconhecimento do aluno pelo meu trabalho e também o reconhecimento da evolução do seu aluno.

Prof. E - Essa parte é mais difícil, a minha concepção de justiça, até por causa de algumas coisas que eu já li, seria você fazer valer, ou tentar fazer valer, alguma coisa que tenha a ver com legislação, alguma coisa do tipo. Mas a justiça em si seria você praticar alguma coisa que traria até algum benefício pra alguém ou que justifique alguma ação.

\section{ESCOLA JUSTA}

Prof. C - Em uma escola justa a gente pode juntar o conceito de colaboração com igualdade e, eu acho que, pra escola justa poderia usar essa colaboração, esse trabalho colaborativo entre os professores teoricamente [...] deveriam fazer em uma instituição pra promover a igualdade dentro da escola.

Prof. A - Pra ser justa, uma escola precisa ter todos os recursos pra atender o aluno. Eu acho que acima de tudo o ensino tinha que ser centrado no aluno e não no professor.

Prof. D - Igualdade no sentido de conhecimento específico que eles precisam aprender e até mesmo que eles gostariam de aprender. Alguns tópicos eu até deixo um pouco livre pra eles escolherem [...]. Visando atingir o que eles precisam e também o que eles gostam.

Prof. B - Aquela em que os professore não usam o poder que eles têm de reprovar ou não pra quase torturar os alunos, porque os alunos têm que dar mais atenção àquela disciplina, então eles acabam deixando a desejar em outras.

\section{JUSTIÇA E INJUSTIÇA NA PROFISSÃO}

Prof. B - Principalmente dos colegas acharem que o inglês é subdisciplina, que não é importante. É a primeira injustiça. Eu acho que justo o que a gente passa para o aluno, essas noções que a família não consegue passar, né? Isso já é uma questão bem justa. Essa questão de você conseguir um contato maior, às vezes, com uma turma ou com algum aluno e você realmente conseguir acompanhar esse desenvolvimento dele, isso acaba sendo muito gratificante, essa evolução que 
você consegue acompanhar, às vezes, de um aluno que estava ali pra aprender e realmente aprendeu o que estava querendo ensinar. Pra mim já é uma questão mais justa.

Prof. A - Bem, o que é injusto na profissão de professor é que a gente às vezes não pode se dedicar basicamente a uma instituição. $\mathrm{E}$, às vezes é um desejo de muitos professores se dedicarem a um local de trabalho. E como a gente tem esse problema da má remuneração ou da baixa remuneração a gente acaba tendo que ter mais de um trabalho: público e particular.

Prof. C - Normalmente o professor considera injusta a remuneração. Justo é a possibilidade de aprofundar os conhecimentos com titulações maiores.

\section{INJUSTIÇAS COMETIDAS}

Prof. A - Quando eu tento nivelar, por cima, nem todos os alunos acompanham. Então às vezes eu saio da universidade mal porque eu não consegui levar aquele aluno onde ele esperava chegar. Mesmo sabendo que n fatores influenciam, eu ainda fico pensando que é injustiça com eles quando eu não consigo levá-los ao nível acima.

Prof. D - Não me dedicar com mais afinco, conhecer melhor o meu aluno, conhecer melhor o meu colega de trabalho. Isso é bem injusto. Eu acho que justo o que a gente passa para o aluno, essas noções que a família não consegue passar, né? Isso já é uma questão bem justa.

Prof. B - Não dar atenção que o aluno deveria receber, ou, então, você não se preparar para dar aquela aula, porque às vezes você poderia dar uma aula melhor e não consegue até por falta de tempo ou por falta de incentivo mesmo, falta de ânimo, principalmente as aulas do fim do dia.

Sugestões para a efetivação da escola justa.

Prof. A - A mudança de pensamento do professor. Se o professor pensar que ele poderia ser, não um professor, daqueles de [...] até mesmo a hierarquia na sala de aula, onde ele fica em pé na frente e os alunos sentados como se fossem submissos a ele, se eles pensassem mais em colaborar com a vida acadêmica, profissional no aluno, em vez de usar a sala de aula para impor o conhecimento que ele estudou tantos anos para deter, é uma sugestão bem interessante. E eles poderiam, em vez de criticar as conquistas dos outros, eles poderiam se espelhar.

Prof. B - Se na legislação, por exemplo, está dizendo a universidade deve transmitir conhecimentos, não só teóricos, mas também, conhecimentos de vida. Seria justo que houvesse participação da comunidade, dos pais, dos alunos e da comunidade escolar. Isso seria um tipo de justiça a ser praticada dentro da universidade, por exemplo. 
Prof. B - Uma escola justa, primeiro ela teria que ter uma infraestrutura boa pra receber o aluno, porque eu vejo assim, na parte de, começando por infraestrutura, a parte física da escola, é que às vezes, a gente tem essa questão de acessibilidade.

Prof. C - A escola justa seria uma escola mais inclusiva. E que também o professor também pudesse dar opinião, que às vezes a gente sabe que tem pessoas muito arbitrárias, não só da direção acadêmica, mas também da parte do governo, a parte gerencial.

Prof. D - Ter uma relação mais estreita com os profissionais dentro da escola e, também, ter uma relação mais estreita com a direção da escola, pra saber o que está acontecendo, porque às vezes a parte pedagógica não consegue passar para o professor se o aluno tem algum problema familiar, ou alguma defasagem na aprendizagem

Prof. E - Infraestrutura e equipamentos atualizados para a flexibilização curricular e maior condições para a pesquisa e para a formação profissional.

\section{DISCUSSÃO DOS RESULTADOS E CONCLUSÕES}

As concepções que se tem acerca de justiça são tão diversas quanto os princípios utilizados para defini-la. Assim, há autores que defendem a perspectiva universalista, que afirma que ser justo é tratar da mesma forma os seres que são iguais em certo ponto de vista, que possuem uma mesma característica, a única que se deve levar em conta na administração da justiça. Essa perspectiva encontra como um de seus defensores Rawls (2008), afirmando que uma sociedade pode ser considerada justa quando todos os cidadãos adotam a mesma concepção de justiça, atuando conforme os princípios aceitos por todos como justos. Assim, segundo essa concepção, o acesso aos bens e às oportunidades deve ser igual a todos os cidadãos.

Dubet (2010) é outro estudioso alinhado à perspectiva universalista de justiça, trazendo o conceito de meritocracia como um princípio de justiça que integra diferenças individuais e desigualdades sociais, o que resulta na promoção do equilíbrio e da eficácia global da sociedade, já que sem mérito não haveria outro modo de distribuição dos indivíduos num escalonamento de estratificação social, a não ser aquele das propriedades herdadas, obtidas pelo nascimento.

Dubet (2004) acredita que deve ser oferecida a todos igualdade de oportunidades, a fim de se minimizarem as desigualdades na sociedade em que estão inseridos. Assim, ele propõe a mesma educação para todos de modo que haja igualdade de competição, onde os melhores são recompensados. Entretanto, ele propõe que os "vencidos" não sejam culpabilizados por seus fracassos, mas, 
sim, auxiliados a ultrapassar as barreiras das dificuldades. Portanto, o mérito, mesmo com uma pitada de crueldade, é o sistema mais justo.

Contrariando as posições universalistas, alguns autores defendem a justiça sob a perspectiva pluralista como Walzer (2003) um dos autores mais representativos dessa corrente. Ele propõe uma sociedade organizada em esferas - escola, saúde, família - que possuem características e necessidades próprias. Por isso, é justo que a distribuição das diferentes oportunidades e dos diferentes bens sociais - segurança, bem-estar, educação, dinheiro, trabalho, tempo livre, poder político, amizade, igualdade - seja feita de acordo com a necessidade, o mérito e o mercado de cada um desses mundos.

Criticando o paradigma distributivo da justiça, defendido pelas perspectivas universalista e pluralista, Young (1990) vê dois problemas: o primeiro é que este paradigma tende a conceber a justiça social como a repartição de bens materiais e a distribuição de posições sociais; o segundo é que, quando se estende aos bens sociais imateriais - poder de decisão, oportunidade e respeito próprio - estes passam a ser representados como "coisas estáticas", em vez de processos que regem as relações sociais. Assim, a autora afirma que o paradigma distributivo é o reforço da injustiça pela universalização das normas dos grupos dominantes a partir de políticas de distribuição que são cegas à diferença.

Young (1990) apresenta, então, um conceito de justiça, que objetiva a eliminação da dominação, imposta pelas condições institucionais que impedem as pessoas de participar na determinação de suas ações, e da opressão, que se refere aos processos institucionais que impedem as pessoas de desenvolver suas capacidades, estando, segundo Estêvão (2004), “interessada numa política valorizadora da diferença” (p.30). Essa perspectiva é conhecida como radical. Para Young (1990), se não existissem as imposições das condições institucionais, cada indivíduo agiria conforme suas capacidades não havendo qualquer paradigma que colocasse as pessoas num mesmo patamar ou numa pretensa uniformidade.

Apresentados os diversos conceitos, é possível observar que as questões de justiça se correlacionam a diversos elementos, principalmente de igualdade, de liberdade, de mérito, de poder e autoridade, "que vão condicionar, de modo particular, a maneira como pensamos a educação e o modo como as escolas devem ser organizadas para cumprirem as suas finalidades" (ESTÊEÃO, 2004, p. 35).

Da mesma forma que em todos os setores da sociedade, também na educação a justiça tende a ser entendida como igualdade de oportunidades e mérito, ou seja, uma educação justa é aquela que oferece a todos as mesmas oportunidades e aqueles que merecem são recompensados alcançando as melhores notas, recebendo a melhor educação, conseguindo os melhores empregos. 
Certamente, existem outras questões acerca da justiça que devem complementar, por exemplo, o modelo meritocrático para tornar a educação justa para todos. Então, é necessário lançar mão da discriminação positiva, que tem como objetivo levar em conta as desigualdades reais existentes entre os alunos e tentar, de alguma forma, minimizá-las com, por exemplo, estudos dirigidos, atividades esportivas e culturais.

Também para complementar o modelo meritocrático e não permitir que este leve à manutenção das desigualdades, as escolas justas devem garantir competências mínimas abaixo das quais ninguém deveria ficar. É claro que essas competências mínimas devem ter alguma utilidade para a formação social e profissional do cidadão, pois "há também uma grande injustiça em deixar os alunos do Ensino Médio e os estudantes universitários envolverem-se em formações desprovidas de utilidade social" (DUBET, 2004, pág.549).

Embora todas essas questões sejam essenciais para a construção de uma escola justa, elas têm como prioridade o tratamento dispensado ao aluno. Entretanto, é importante pensar numa escola justa como aquela que visa a atender não somente os alunos, mas a comunidade escolar como um todo, incluindo o professor, que é parte importantíssima no processo de transformação da escola.

Nessa linha, Estevão (2004) traz o conceito de justiça complexa, que articula intimamente outras concepções, como a de liberdade, de equidade, de igualdade, mérito, de poder e autoridade, entre outros, que irão condicionar, de maneira particular, o modo como pensamos a educação e a forma como as escolas devem organizar-se para o cumprimento das suas finalidades. Os conceitos de justiça e educação são, na verdade, inseparáveis.

Nessa concepção, a escola se encontra em um âmbito público de comunicação e conflito, de direitos e deveres que ultrapassam os limites de seus muros, e que é pautada em valores como a liberdade, igualdade, equidade, solidariedade, cooperação etc. Ela é percebida como organização dialógica que tem como base os princípios da sinceridade, da inclusão ou da participação de todos os comprometidos no diálogo; da revisão argumentativa, da reciprocidade, de uma gestão democrática em sua realidade; do respeito pela diferença e singularidade do outro, emocionalmente, caracterizando assim o conceito de justiça, que faz uma articulação ao de educação, mantendo-os atrelados entre si.

À luz dessa discussão, é possível perceber que os professores que participaram da pesquisa, ao tratar de justiça, escola justa e de sugestões para a efetivação da escola justa trazem elementos que podem ser identificados com a justiça universalista, com a ideia de que as oportunidades devem ser iguais para todos; que a justiça está relacionada a leis e normas, portanto a seu aspecto jurídico- 
legal; trazendo para si o significado de justiça como o reconhecimento de seu trabalho, revelando, involuntariamente, um princípio da perspectiva redistributiva de Fraser (2009).

Para os professores, a escola justa é aquela que deve ser organizada para ser igual para todos; como disse um professor, "atende aos seus propósitos, seu planejamento, suas propostas pedagógicas, indo ao encontro dos interesses da comunidade que atende", o que indica uma organização democrático-participativa.

Quando falam de injustiças cometidas, conseguem revelar questões referentes a solidariedade, reciprocidade, participação, elementos alinhados à concepção de justiça complexa. Já quando se manifestam a respeito de injustiças na profissão, o fazem ilustrativamente com casos individuais em que sofrem falta de reconhecimento, salários baixos, confirmando a ideia de que injustiça é aquilo que é perceptível, aquela do cotidiano, ligada às relações interpessoais e de remuneração, ao que Schilling (2013) chama de micro injustiça.

Qualquer modelo de justiça, como afirma Gewirtz (2006) deve confrontarse com o desafio de reduzir as iniquidades da distribuição, reconhecimento e de associação que oprimem e marginalizam grupos, que podem ser representados por alguns dos alunos que nos responderam a este questionário.

Talvez também melhor que tentar afirmar os direitos dos grupos oprimidos de modo a serem tratados igualmente, Fraser advoga estratégias transformadoras que envolvem a desconstrução de categorias sociais existentes e a reconstrução radical das relações de produção.

Parece não haver dúvidas também que uma escola justa preservaria melhor a dignidade e a autoestima dos que não fossem tão bem-sucedidos, mas tal supõe outros tipos de ação, desde logo, a afirmação do papel educativo e cultural da escola não apenas ao nível da instrução, mas também nas atividades culturas e desportivas, na organização da própria vida escolar, no atendimento dos alunos fora da classe. No caso dos professores, a dignificação de seu trabalho, a garantia do respeito por suas idiossincrasias e a valorização de seus saberes e fazeres.

Consideramos que, além da contribuição teórico-metodológica que os resultados desta pesquisa trarão para o campo educacional, também expressam relevância acadêmico-científica, na medida em que irâo possibilitar melhor compreensão de concepções que fundamentam as propostas de organização escolar mais justas para a educação e o ensino brasileiros. 


\section{REFERÊNCIAS}

DUBET, F. Les Places et les chances. Repenser la justice sociale. Paris: La République de Idées/Seuil, 2010.

DUBET, François. O que é uma escola justa? Cad. Pesquisa, São Paulo, v. 34, n. 123, p. 539-555. dez. 2004. Disponível em http://www.scielo.br/scielo. php?script $=$ sci_arttext\&pid $=$ S0100-15742004000300002\&lng $=$ pt\&nrm $=$ iso $>$. Acesso em 22 jun. 2010.

DUBET, F. Le déclin de l'institution. Paris: Seuil, 2002.

ESTEVÃO, Carlos Vilar. Educação, globalizações e cosmopolitismos: novos direitos, novas desigualdades. Rev. Port. de Educação, , vol.22, no .2, p.35-52. 2009. ISSN 0871-9187.

ESTEVÃO, Carlos Vilar. Novas desigualdades, novos direitos e cosmopolitismos: para uma política educacional e uma administração da educação cosmopolíticas. Caderno de Pesquisa: Pensamento Educacional, volume 4, no. 7, jan-jun, 115137. 2009.

ESTÊVÃO, Carlos Alberto Vilar. Educação, justiça e democracia: um estudo sobre as geografias da justiça em educação. São Paulo: Cortez, 2004.

FRASER, N. Justice Interruptus: Critical Reflections on the "Postsocialist" Condition. Cambridge: Routledge, 1997.

FRASER, N. Reenquadrando a justiça em um mundo globalizado. Lua Nova [online]. 2009, n.77,p. 11-39. ISSN 0102-6445. doi: 10.1590/S010264452009000200001 .

FRASER, N. Reframing justice in a globalizing world. D. Held \& A. Kaya (Eds.), Global Inequality. Cambridge: Polity Press, 2007, p. 252-272.

GEWIRTZ, S. Towards a contextualized analysis of social justice in education. Educational Philosophy and Theory 1, (1), 2006. p.69-81

GEWIRTZ, S. Conceptualizing Social Justice in Education: Mapping the Territory. Journal of Education Policy, 13(4), 2002. p. 469-484. 
LYNCH, K. The Limits of Liberalism for the Promotion of Equality in Education. Association for Teacher Education in Europe - 20th Annual Conference, Oslo, 3-8 September, 1995.

MINAYO, M. O Desafio do conhecimento. São Paulo: Hucitec, 1996.

ORLANDI, Eni P. A linguagem e seu funcionamento. As formas do discurso. Campinas: Pontes, 1987.

POWER, S.; GEWIRTZ, Sharon (2001) Reading education action zones. J. Ed. Policy, 6, 1, 39-51.

STURMAN, A. Social Justice in Education, Melbourne: ACER, 1997.

RAWLS, John. Uma Teoria da Justiça. 3 ed. São Paulo: Martins Fontes, 2008.

SCHILLING, F. Igualdade, desigualdade e diferenças: o que é uma escola justa? Educação e Pesquisa, São Paulo, v. 39, n. 1, p. 31-48, jan./mar. 2013

WALZER, M. Esferas da justiça: uma defesa do pluralismo e da igualdade. São Paulo: Martins Fontes, 2003.

YOUNG, I. Justice and the politics of difference. Princeton: Princeton University Press, 1990.

DINAIR LEAL DA HORA é graduada em Pedagogia e Letras pela UFPA. Mestre em Educação pelo PUC/SP. Doutora em Educação pela UNICAMP. Possui Pós-Doutorado em Administração Escolar e Economia da Educação pela USP e Pós-Doutorado em Sociologia das Organizações Educativas pela UMINHO. É Professora Permanente do Programa de Pós-Graduação em Currículo e Gestão da Escola Básica/UFPA e Vice Coordenadora do Programa de Epidemiologia e Vigilância em Saúde do IEC. E-mail: tucupi@uol.com.br

LUZIANE SAID COMETTI LELIS possui graduação em Pedagogia (Administração e Orientação Educacional), Especialização em Educação e Informática pela Universidade Federal do Pará. É Coordenadora Pedagógica na SEMEC/BELÉM, Coordenadora do Laboratório de Informática e professora da Educação Básica na SEDUC/PARÁ. Atualmente é mestranda do Programa de Pós-Graduação em Currículo e Gestão da Escola Básica/UFPA. E-mail: luziane.bim@gmail.com 